\title{
CONGENITAL DIAPHRAGMATIC HERNIA IN NEONATE EXPERIENCE IN A TEACHING HOSPITAL
}

\author{
Khan $\mathrm{SE}^{1}$, Siddiq $\mathrm{AKMZ}^{2}$, Nessa $\mathrm{M}^{3}$
}

\begin{abstract}
Introduction: Congenital diaphragmatic hernia (CDH) is one of the major surgical causes of respiratory distress in neonates. Reported survival averages $60 \%$ but may be significantly lower. Pulmonary hypertension and pulmonary hypoplasia are recognised as two corner stones of the pathophysiology of CDH.
\end{abstract}

Objective: Objective of the study was to evaluate the outcome of this birth defect in Bangladesh situation.

Method: This retrospective study was carried out at the Department of Paediatric Surgery of Combined Military Hospital, Dhaka over a period of five years. During this period a total of 8 neonates of CDH were admitted in this hospital. All the data were collected from record sheet and were compiled.

Result: Age of patients ranged from 1 day to 20 days. Out of 8 neonates $5(62.50 \%)$ were male and $3(37.50 \%)$ were female. All patients were diagnosed postnatally. All the 8 neonates had Bochdalek type of CDH. Seven patients $(87.50 \%)$ had left sided hernia. Two patients $(25 \%)$ died before operation in the stabilization phase while on ventilator and $6(75 \%)$ were operated. Out of these 6 patients, 5 (left sided) were operated through abdominal route and 1 (right sided) was approached through thorax. Overall outcome was satisfactory in 5 neonates and one died.

Conclusion: Early intervention can result good prognosis in CDH.

Key words: Congenital diaphragmatic hernia, neonate, Bochdalek type

\section{Introduction}

A congenital diaphragmatic hernia $(\mathrm{CDH})$ is a birth defect or abnormality that occurs before birth as a foetus is forming in the mother's uterus ${ }^{1}$. It should be diagnosed in prenatal period and promptly referred to a tertiary centre for imaging, genetic testing and multidisciplinary counselling. It is one of the major surgical causes of respiratory distress in neonates. CDH occurs in approximately 1 in every 2000-4000 babies and accounts for $8 \%$ of all major congenital anomalies $^{2-4}$. The diagnosis of CDH is often made on a prenatal ultrasound (USG) examination and is accurate in $40 \%$ to $90 \%$ of cases ${ }^{5}$. The 3 basic types of $\mathrm{CDH}$ are the posterolateral Bochdalek hernia, the anterior Morgagni hernia and the hiatus hernia ${ }^{6}$. Affected neonates are born with a complex interface of pulmonary hypoplasia and pulmonary hypertension ${ }^{7}$. The incidence of associated anomalies in neonates with $\mathrm{CDH}$ ranges from $10 \%$ to $50 \%$ and the final outcome depends much on it ${ }^{8,9}$.

The left sided Bochdalek hernia having a male preponderance (1.5:1) occurs in approximately 80$90 \%$ of $\operatorname{cases}^{6}$. Morgagni hernia are rare and usually not diagnosed in neonatal period. The emphasis in postnatal management has shifted from the neonatal surgical emergency approach to a delayed procedure designed to deal with pulmonary hypoplasia and the pulmonary vascular abnormalities ${ }^{10,11}$. Despite advances in postnatal care, patients with $\mathrm{CDH}$ suffer substantial morbidity and mortality ${ }^{12}$. Reported survival averages $60 \%$ but may be significantly lower. Neonates with $\mathrm{CDH}$ are critically ill, but can expect better survival if other serious anomalies are not present, however, significant morbidities can exist in the survivors ${ }^{13-15}$. Young CDH survivors continue to have ongoing medical problems and a high incidence of motor and language problems ${ }^{16}$. Neonates with CDH show a wide range of anatomic and physiologic abnormalities, making it difficult to compare the efficacy of management protocol between institutions ${ }^{8}$.

This study was done to share experience with $\mathrm{CDH}$ in neonate and the early results of operative treatment.

\section{Material and Method}

This retrospective study was carried out at the Department of Paediatric Surgery, Combined Military Hospital, Dhaka from July 2004 to June 2009. During this study period a total of 8 neonates of $\mathrm{CDH}$ were admitted in the mentioned hospital. Particulars of all those patients were recorded which included age, sex, weight etc. Detailed history was taken and thorough clinical examination done in all the patients. Relevant investigations (plain x-ray,

1. Lt Col Shams-Ud-Din Elias Khan MBBS, MS, Classified Specialist in Paediatric Surgery, CMH, Dhaka; e-mail: shams4raiyan@yahoo.com, 2. Lt Gen A K M Zafrullah Siddiq MBBS, FCPS, Former DGMS, Bangladesh Armed Forces; 3. Lt Col Meherun Nessa MBBS, MS, Classified Specialist in Surgery, CMH, Dhaka. 
contrast x-ray, USG, blood chemistry, arterial blood gas etc) were done as required (Fig1 \& 2). All the patients with $\mathrm{CDH}$ were operated by open method after initial stabilization. Postoperatively the patients were followed up at the end of 1 st month and 3rd month. Relevant clinical information, investigation results, operative procedures, post operative sequelae and follow up results were documented.

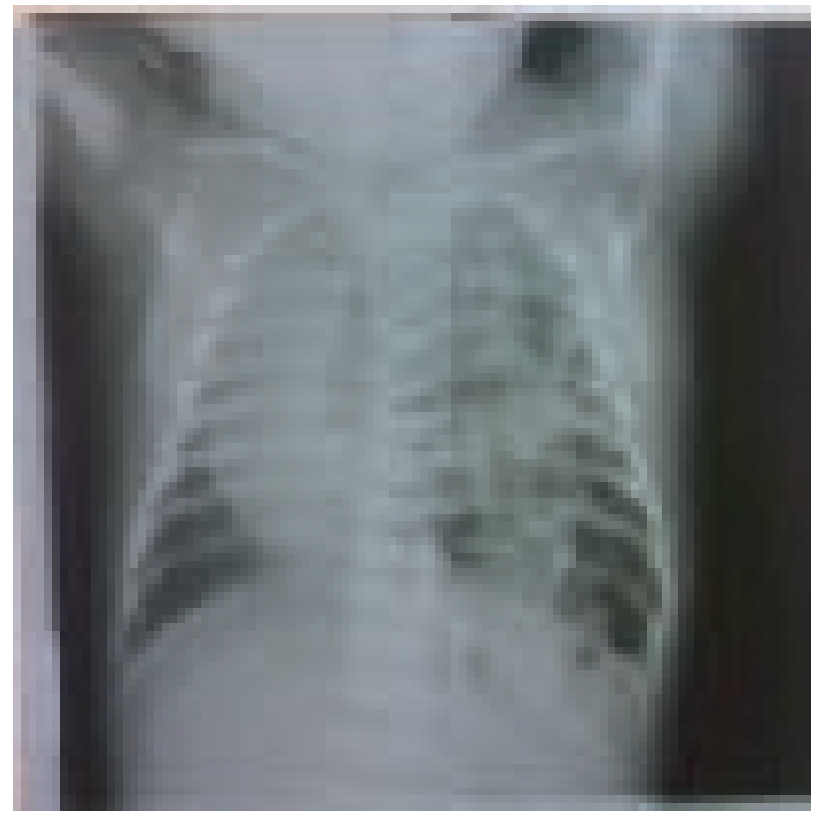

Fig-1: Plain x-ray chest showing left sided Bochdalek hernia

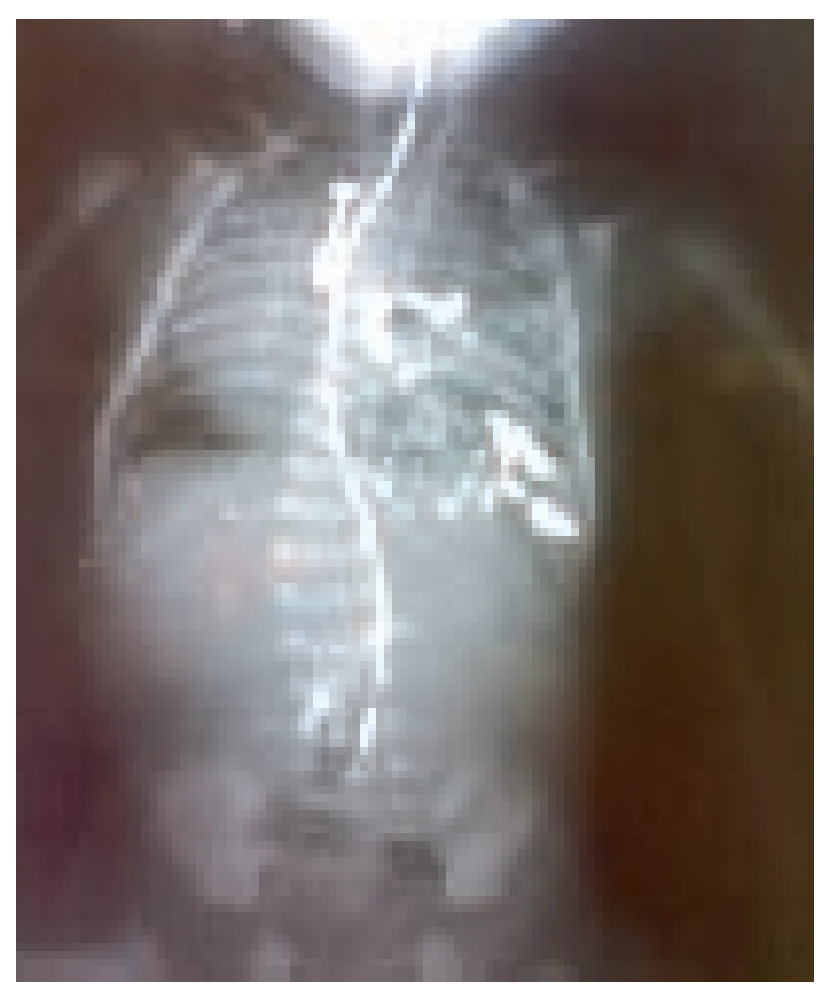

Fig-2: Contrast x-ray of upper GITshowing left sided Bochdalek hernia

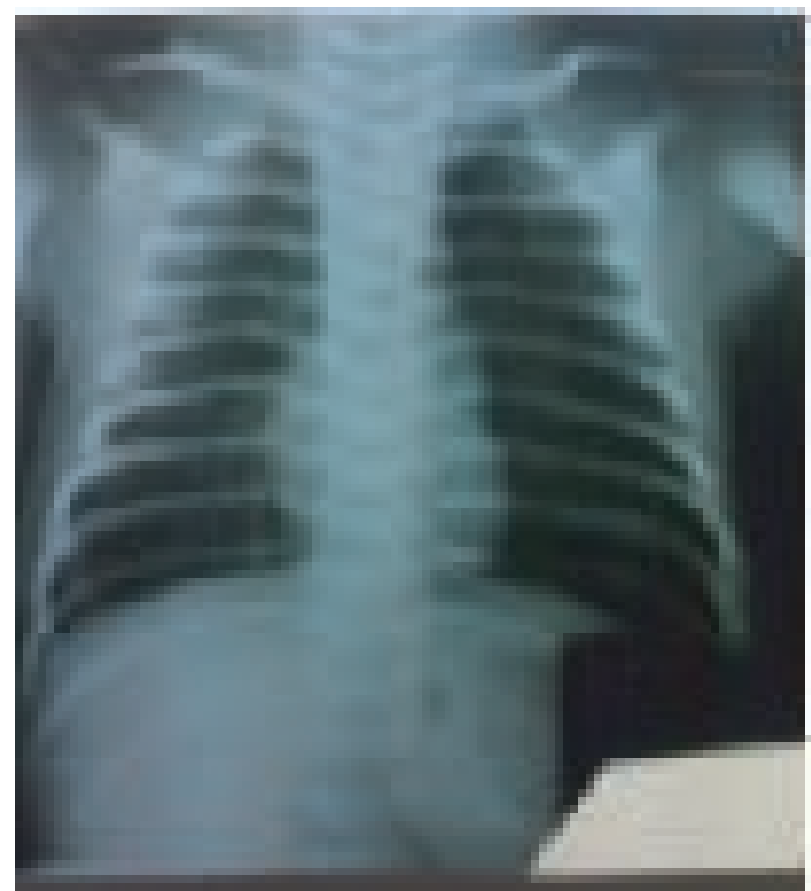

Fig-3: Plain x-ray chest of a case of left sided Bochdalek hernia after surgery

\section{Result}

Out of total 8 neonates of $\mathrm{CDH} 6$ neonates (75\%) had age less than 1 week and $2(25 \%)$ had 1 week to 1 month. Age ranged from 1 day to 20 days. Five neonates $(62.50 \%)$ were male and $3(37.50 \%)$ were female. All the 8 neonates had Bochdalek type of $\mathrm{CDH}$ and were diagnosed postnatally. Seven patients $(87.50 \%)$ had left sided hernia and 1 $(12.50 \%)$ had right sided lesion. Two neonates $(25 \%)$ died before operation in the stabilization phase while on ventilator and $6(75 \%)$ were operated. Out of these 6 patients, 5 (left sided) were operated through abdominal route and 1 (right sided) was approached through thorax. Synthetic mesh was not required in any of the cases. One patient died on 2 nd post operative day. All other five recovered satisfactorily and on regular follow up.

\section{Discussion}

$\mathrm{CDH}$ is a relatively common birth defect. Fetuses with CDH who have a "poor prognosis" with postnatal treatment now can be identified early (before 25 weeks' gestation) on the basis of liver herniation, and a low lung to head ratio (LHR) ${ }^{17}$. The use of a protcolized management that included antenatal assessment, antenatal steroid, planned delivery, prophylactic surfactant, pressure limited gentle ventilation, permissive hypercarbia and hypoxia and extracorporeal membrane oxygenation (ECMO), if indicated, has improved the outcome in high risk population ${ }^{18}$. 
In this study, all the 8 neonates had Bochdalek type of $\mathrm{CDH}$. Incidence of Bochdalek hernia ranges from 90-95\% among all CDH and mostly this type present in neonatal period ${ }^{19}$. None of them had antenatal diagnosis although antenatal diagnosis is possible in $40-90 \%$ of the cases ${ }^{5}$. This may be because of the fact that maternal USG is not routinely and meticulously done throughout the country. Out of 8 neonates with $\mathrm{CDH}, 6$ (75\%) patients presented to hospital in 1 st week of their life. Neonates most commonly present with the stigmata of cyanosis and respiratory distress in the first few days of life, although a later presentation is possible ${ }^{2,5,7}$. Among 8 neonates, 5 were male and 3 were female making a male to female ratio of 1.7:1. Reported male-female ratio is 1.5:16. Seven neonates $(87.50 \%)$ had left sided Bochdalek hernia. Left sided hernias are more commonly (80-90\%) observed type reported in various studies ${ }^{3,5,6}$. Associated anomalies in neonates with $\mathrm{CDH}$ is $10-$ $50 \%$. But in this series, none of the 6 operated patients had associated anomalies. The 2 neonates that died before operation might have hidden anomalies. Autopsy was not done. All patients were operated after initial resuscitation and stabilization. ECMO, high frequency oscillatory ventilation, dedicated neonatal surgical intensive care unit (ICU) were not available in the centre. Outcome was satisfactory in 5 cases. Survival rate of patients with $\mathrm{CDH}$ is reported $60-80 \%{ }^{2,6,19}$. CDH may result in severe respiratory insufficiency with a high morbidity $^{20}$. A poor prognosis, however, is associated with polyhydramnios, presence of foetal stomach in the chest and an early presentation (i.e., distress in the first few hours of life).

\section{Conclusion}

$\mathrm{CDH}$ represents a treatable cause of perinatal morbidity and mortality. Outcome of treatment often depends on associated anomalies. Significant longterm morbidities like developmental delay, poor growth, gastro oesophageal reflux disease, hearing loss and musculoskeletal abnormalities can exist in the survivors. As such they require regular followup for long time.

\section{Refernces}

1. Deprest JA, Gratacos E, Nicolaides K, et al. Changing perspectives on the perinatal management of isolated congenital diaphragmatic hernia in Europe. Clin Perinatol 2009 Jun; 36(2): 329-347 IX.
2. Lugo-Vicente HL. Pediatric Surgery Handbook. 1st ed. San Juan: Puerti Rico; 2002. p.18-20.

3. Arensman RM, Bambini DA. Congenital diaphragmatic hernia and eventration. In: Ashcraft KW, editor. Pediatric Surgery. 3rd ed United States of America: WB Saunders Company; 2000. p.300-317.

4. Diaphragmatic hernia. Medline Plus Available at: www. nlm.nih.gov/medlineplus/ency /article/001135.htm

5. Stolar CJH, Dillon PW. Congenital diaphragmatic hernia and eventration. In: Grosfeld JL, O'Neill JA, Coran AG, Fonkalsrud EW, editors. Pediatric Surgery. 6th ed. United States of America: Mosby Inc, 2006. p.931-954.

6. Steinhorn RH, Hollands CM. Congenital diaphragmatic hernia. Medscape Refeence Drug Diseases \& Procedure. Available at: www.emedicine.com/PED/topic2603.htm

7. Stolar CJH. Congenital diaphragmatic hernia. In: Spitz L, Coran AG, editors. Rob \& Smith's Operative Pediatric Surgery. 6th ed. United States of America: Hodder Arnold, 2006.p.153-158.

8. Wilson JM, Lund DP, Lillehei CW, et al. Congenital diaphragmatic hernia- a tale of two cities: the Boston experience. J Pediatr Surg 1997 Mar; 32(3): 401-405.

9. Tracy TF, Luks FI. Diaphragmatic hernias and eventration. In: Ziegler MM, Aziz Khan RG, Weber TR, editors. Operative Pediatric Surgery. 1st ed. United States of America: The Mc Graw-Hill Companies; 2003. p.481-498.

10. Clark RH, Hardin WD Jr, Hirschl RB, et al. Current surgical management of congenital diaphragmatic hernia: a report from the Congenital Diaphragmatic Hernia Study Group. J Pediatr Surg 1998 Jul; 33(7): 1004-1009.

11. Bohn DJ, Pearl R, Irish MS, et al. Postnatal management of congenital diaphragmatic hernia. Clin Perinatol 1996 Dec; 23(4): 843872 .

12. Albanese CT, Lopoo J, Goldstein RB, et al. Fetal liver position and perinatal outcome for congenital diaphragmatic hernia. Prenat Diagn 1998 Nov; 18(11): 1138-1142.

13. Langman MR Jr, Kays DW, Ledbetter DJ, et al. Congenital diaphragmatic hernia. Epidemiology and outcome. Clin Perinatol 1996 Dec; 23(4) 671-688

14. Nobuhara KK, Lund DP, Mitchell J, et al. Long term outlook for survivors of congenital diaphragmatic hernia. Clin Perinatol 1996 Dec; 23(4): 873-887.

15. Kays DW, Langham MR Jr, Ledbetter DJ, et al. Detrimental effects of standard medical therapy in congenital diaphragmatic hernia. Ann Surg 1999 Sep; 230(3) 340-348.

16. Friedman S, Chen C, Chapman JS, Jeruss S, Terrin N, Tiqhiouart H et al. Neurodevelopmental outcomes of congenital diaphragmatic hernia survivors followed in a multidisciplinary clinic at ages 1 and 3. J Pediatr Surg 2008 Jun; 43(6): 1035-1043.

17. Harrison MR, Mychaliska GB, Albanese CT, et al. Correction of congenital diaphragmatic hernia in utero IX: fetuses with poor prognosis (liver herniation and low lung-to-head ratio) can be saved by fetoscopic temporary tracheal occlusion. J Pediatr Surg 1998 Jul; 33(7) 1017-1022.

18. Finer NN, Tierney A, Etches PC, et al. Congenital diaphragmatic hernia: developing a protocolized approach. J Pediatr Surg 1998 Sep; 33(9):1331-1337.

19. Dave S, Gupta DK. Text book of Neonatal Surgery. 1st ed. India: Modern Publishers; 2000. p.374-393

20. Janssen DJ, Zimmermann LJ, Cogo P, et al. Decreased surfactant phosphatidylcholine synthesis in neonates with congenital diaphragmatic hernia during extracorporeal membrane oxygenation. Intensive Care Med 2009 Oct; 35(10): 1754-1760.e pub 2009 Jul 7. 